\title{
UN ACHEGAMENTO A SAN GONZALO
}

Florentino Pérez García

Universidade de Santiago de Compostela doi:10.17075/mucnoc.2014.019 

Forcadela, M. / T. López / D. Vilavedra (coords.) (2014): Mil e un cunqueiros. Novas olladas para un centenario, Santiago de Compostela, Consello da Cultura Galega. doi:10.17075/mucnoc.2014. pp. 385-414

San Gonzalo podería ser descrito brevemente como unha haxiografía de Gonzalo Arias, bispo de Mondoñedo, na cal é posíbel detectar algúns dos trazos mediante os que é caracterizada xeralmente a produción literaria de Cunqueiro, como, por exemplo, a utilización de recursos propios da narrativa oral, as referencias culturalistas ou o uso de materiais míticos e fantásticos.

O libro foi publicado por primeira vez en 1945, so o pseudónimo de Álvaro Labrada, pola Editora Nacional en Madrid. En 1968, a narración foi recollida no volume Flores del año mil y pico de ave, editado por Taber en Barcelona, onde figura xa como autor Álvaro Cunqueiro. Despois da morte do mindoniense, Flores del año mil y pico de ave tivo dúas edicións na colección «Biblioteca Breve» de Seix Barral, en 1984 e 1990. Posteriormente foi incluído no primeiro volume das Obras literarias en castellano de Cunqueiro editadas pola Fundación José Antonio de Castro en 2006. Unha tradución para o galego de San Gonzalo foi publicada pola editorial Ir Indo no ano 2000. No ámbito galego, o principal interese espertado pola obra débese ao plaxio dalgúns fragmentos d'A romeiría de Gelmírez de Otero Pedrayo ${ }^{1}$.

Proporemos, a continuación, unha aproximación á novela San Gonzalo desde unha perspectiva sistémica. Un estudo en profundidade deste tipo, cuxo obxectivo final sería determinar a posición e función da obra nos sistemas literarios onde funciona, excedería os límites deste traballo. Con todo, cremos que as liñas que apuntaremos poden ser útiles á hora de analizar a traxectoria xeral de Cunqueiro, así como para dar conta de cuestións como a do diferente status que posúe o autor na literatura galega e na española. Faremos, polo tanto, uns apuntamentos metodolóxicos como punto de partida. Seguindo a Pierre Bourdieu, consideramos as publicacións e reedicións de San Gonzalo en tanto que tomas de posición no campo

1 Véxase Rodríguez Fer (1992). 
literario $^{2}$. As diferentes edicións da obra constitúen diferentes tomas de posición na medida en que se produzan mudanzas no espazo dos posibeis ${ }^{3}$.

Deberemos ter en consideración o asunto da nacionalización dos sistemas literarios, xa que, no caso que nos ocupa, resulta determinante nos procesos de canonización e nas relacións que se estabelecen entre sistemas. A propósito de Cunqueiro, isto xa foi sinalado desde perspectivas parcialmente diverxentes da que nós adoptamos: Rexina Rodríguez Vega, analizando a recepción de Cunqueiro na literatura española, fala dunha «clara percepción dos valores fantásticos e paródicos como esencialmente alleos á tradición propia» (Rodríguez Vega 2001: 208). Así, a recepción crítica de Cunqueiro estaría centrada sobre todo en resaltar as carencias da tradición nacional entendida como realista, o que levaría a unha lectura en clave exótica da produción do mindoniense. Ademais, sinala a autora que a través da atribución de certas características (humor, fantasía, parodia) á produción dunha serie de axentes galegos actuantes no campo español (ValleInclán, Wenceslao Fernández Flórez, Torrente Ballester, o mesmo Cunqueiro) «a súa común raíz galega acostuma a presentarse como elemento determinante dentro dun discurso máis próximo á etnopsicoloxía que ó ámbito estrictamente literario» (Rodríguez Vega 2001: 210). Por outra parte, Xoán González-Millán sinala:

2 O campo é unha rede de relacións obxectivas (de dominación ou subordinación, de complementariedade ou antagonismo, etc.) entre posicións: por exemplo, a que corresponde a un xénero como a novela ou a unha subcategoría como a novela de sociedade, ou, desde outro punto de vista, a que identifica unha revista, un salón ou un cenáculo como os lugares de reunión ou emblemas totémicos dun grupo de produtores. Cada posición está obxectivamente definida pola súa relación obxectiva coas outras posicións ou, noutros termos, polo sistema de propiedades pertinentes, é dicir, eficientes, que permiten situala en relación con todas as outras na estrutura de distribución global das propiedades. Todas as posicións dependen, na súa existencia mesma, e nas determinacións que impoñen aos seus ocupantes, da súa situación actual e potencial na estrutura do campo, é dicir, na estrutura do reparto das especies de capital (ou de poder) cuxa posesión determina a obtención de beneficios específicos (como o prestixio literario) que están en xogo no campo. (Bourdieu 2004: 61).

3 Cada toma de posición (temática, estilística, etc.) defínese (obxectiva e, ás veces, intencionalmente) a respecto do universo das tomas de posición (que corresponden ás diferentes posicións) e a respecto da problemática como espazo dos posibeis que nel están indicados ou suxeridos; recibe o seu valor distintivo da relación negativa que a une ás tomas de posición coexistentes ás cales está obxectivamente referida, e que a determinan delimitándoa. Unha conclusión sería, por exemplo, que o sentido e o valor dunha toma de posición (xénero artístico, obra particular, etc.) cambian automaticamente, mesmo que esta permaneza idéntica, cando muda o universo das opcións substituíbeis que quedan á elección dos produtores e dos consumidores. (Bourdieu 2004: 63). 
Os procesos de canonización de Rosalía de Castro, Álvaro Cunqueiro, Celso Emilio Ferreiro, Neira Vilas ou Blanco-Amor xiran en torno ao principio de representación dunha identidade nacional. As insistentes alusións ao talante fantasioso ou imaxinario da literatura galega, da que se aproveitan determinados críticos para incluír nela autores de expresión non galega (o exemplo de Torrente Ballester), non fan senón demostrar a persistente utilización deste tipo de argumentos sobre a identidade nacional da literatura galega. (González-Millán 1995: 74).

Volvendo ao noso enfoque metodolóxico, trataremos estas cuestións seguindo o desenvolvemento da teoría do polisistema proposto por Elías J. Torres Feijó, isto é, en termos de balizamento entre sistemas ${ }^{4}$. Desta maneira, no espazo sociocultural galego atopamos tendencias protosistémicas ${ }^{5}$ e tendencias subsistémicas ${ }^{6}$. As normas sistémicas ${ }^{7}$ teñen como función delimitar os sistemas e protosistemas, mentres que as normas de repertorio non actúan nun nivel sistémico, senón repertorial. As normas sistémicas poden funcionar en determinados momentos como

4 A proposta de Torres Feijó está orientada á análise «das diferentes redes delimitadas por diferentes balizas ou, num dado espaço social ou sócio-político comum, dos agentes e grupos que concorrem nesse mesmo espaço polo domínio sistémico do mesmo, por imporem a sua rede e/ou apoderar-se da do concorrente. Essa delimitaçom e/ou esse conflito é aqui focado (sem contradizer a visom zohariana) como delimitaçom e/ou conflito entre sistemas (noutro nível, de repertórios nu sistema), evidenciando a articulaçom entre sistema cultural e campo do poder e, em parte polo menos, o papel das lutas naquel nos objectivos dos grupos em confronto neste. Isto, assim, manifesta o carácter construído que essa articulaçom porta, violência simbólica que deve a sua neutralizaçom em sistemas considerados "normalizados" à elaboraçom e imposiçom dumha "crença comunitária», dumha visom de articulaçom harmónica entre o espaço social, as balizas do seu sistema cultural e o corpus identitário que legitima os domínios do campo do poder. Esta distinçom é a que nos permite falar, por exemplo, do sistema literário português delimitável dos outros sistemas e dos outros espaços sistémicos, do sistema literário francês ou colombiano, e nom fazê-lo sinónimo do sistema literário em Portugal, na França ou na Colômbia. (Torres Feijó 2004: 428).

5 Orientadas a conseguir a «configuraçom dum novo sistema segregado do sistema a que se está vinculado» (Torres Feijó 2004: 429).

6 «Práticas que, mantendo especificidades a respeito do sistema originário, nom pretendem impugnar a sua pertença a este (o que, provisoriamente e de forma insuficiente e esquemática, se pode fazer equivaler a 'literaturas regionais' tal como entendidas, por exemplo, no contexto cultural ibérico)» (Torres Feijó 2004: 429).

7 «Som critérios delimitadores que actuam como princípios básicos que se activam nas práticas culturais dos espaços sociais, e de cuja interpretaçom e aceitaçom pola comunidade participante dependem as possibilidades e os modos de obter uso, posiçom e funçom nos sistemas culturais. [...] determina[m] em cada momento histórico o operandum de todos os macro-factores com que interactuam no espaço social em que vigora e som princípios básicos do manual de instruçons que se activam no entendimento e participaçom no tal sistema» (Torres Feijó 2004: 430). 
normas de repertorio, dependendo de que o seu uso estea asociado a tendencias subsistémicas ou a tendencias protosistémicas ${ }^{8}$.

Por último, citaremos o concepto de literatura nacional empregado por César Domínguez (2006: 6-7) no seu estudo da emerxencia literaria. Descríbeo como un subsistema de codificación secundario, que funcionaría da seguinte forma:

Upon contemplating the same examples from a linguistic point of view, one will notice that the exclusions practiced by national literatures are functionally equivalent to those practiced by grammar textbooks with regard to natural languages. Like grammar textbooks, national literatures thus work as systemic self-referential descriptions, self-organizations which differentiate the systemic from the nonsystemic, and are thus essentialist. Thus, the most idiosyncratic function of the national literature as a segregated subsystem of literary life is an additional reorganization, both synchronically and diachronically of its repertoire and products in a simplified way -- sometimes this reorganization being so rigid that it practically refrains from intersecting with the literary life it attempts to describe. (Domínguez 2006: 6).

Non analizaremos polo miúdo as relacións entre o sistema literario español e o que consideraremos como protosistema literario galego, pero formularemos certas cuestións que nos parecen pertinentes nese sentido a partir da descrición das tomas de posición de Cunqueiro que veremos a continuación. De igual maneira, non pretendemos facer un estudo comparado completo do proceso de canonización de Cunqueiro, pero cremos que podemos esbozar hipóteses de traballo de utilidade a ese respecto. Centrarémonos na publicación de San Gonzalo en 1945 e de Flores del año mily pico de ave en 1968, ocorridas en vida de Cunqueiro, aínda que ao final do traballo referirémonos brevemente ás edicións póstumas.

8 «As normas sistémicas flutuam entre esse carácter e um funcionamento como normas de repertório (materiais cujo uso fai mais "genuíno" para os macro-factores em jogo os produtos mas que nom delimitam sistemas), que costuma ser o teito permissível polos grupos dominantes do sistema de que quer emanciparse» (Torres Feijó 2004: 440). 


\section{SAN GONZALO}

Entre 1939 e 1947, Cunqueiro vive e traballa en Madrid. A súa produción literaria na primeira posguerra está marcada polos seus vencellos con Falange e o seu proceso de profesionalización como escritor e xornalista ${ }^{9}$. Despois da fin da Guerra Civil, os falanxistas asumen o control do campo cultural mediante o aparato do estado ditatorial:

El protagonismo de Falange en el campo intelectual, a pesar del confesado antiintelectualismo de los más montaraces, se basa sobre todo en que algunos de los nombres que en esta época se adscriben al falangismo o proceden de él como Laín, Tovar o Ridruejo, pero también Cela, Torrente Ballester, Legaz Lacambra, Rosales, se inscriben entre lo más granado de los frutos — tan amargos- de la quinta intelectual del 36. Desde luego, la voluntad política que está presente en Falange desde el primer momento de ser el referente político del nuevo Estado está presente en la cultura, en la universidad, en el deseo de controlar los organismos de encuadramiento social, especialmente la prensa y su censura, pero también el cine y el teatro o la radio, como hemos comentado. En un plano más elevado, Falange va a hacer también una relevante labor desde la misma guerra civil. Partiendo de una concepción tremendamente elitista de la cultura, pero sin descuidar, fieles a su populismo, los mecanismos de control de la socialización, la propia FET y de la JONS va a tener una serie de revistas y organismos destinados a esta cultura elitista. Unos proyectos dirigidos directamente por el partido y para un público más amplio (revistas como Vértice) y otros más autónomos y, hasta cierto punto generadores de una dinámica propia como es el caso de Escorial. (Ruiz Carnicer 2001:160)

A colaboración de Cunqueiro en xornais falanxistas comezara xa durante a Guerra Civil en Santa Marta de Ortigueira e San Sebastián (Rodríguez Fer 1991: 205 e ss.) e continúa unha vez instalado en Madrid. Colabora con revistas dependentes de Falange a través da Delegación Nacional de Prensa y Propaganda, como Escorial e Vértice (que podemos considerar como proxectos culturais do chamado Grupo de Burgos), así como na primeira época Destino, fundada en Burgos por falanxistas cataláns en 1937. Ademais, participa nalgunhas das revistas culturais

9 Para os datos biográficos baseámonos fundamentalmente en Cunqueiro. Unha biografía, de X. F. Armesto Faginas. Sobre a expulsión de Cunqueiro de Falange en 1943 e a eliminación do seu nome do Registro Oficial de Periodistas en 1944 véxase Franco Grande (1991). 
promovidas por Juan Aparicio (de carácter máis popular que as citadas anteriormente), como Fantasía e La estafeta literaria.

José-Carlos Mainer, en Falange y Literatura, inclúe La historia del caballero Rafael, a primeira novela de Cunqueiro (publicada por Vértice), nunha liña que denomina «los caminos de la fantasía», caracterizada polo seu escapismo. O caso de San Gonzalo parécenos diferente. Foi publicado pola editorial do Estado, Editora Nacional, dirixida por Laín Entralgo, nunha colección de biografías de formato rústico, «Breviarios de la vida española». Podemos relacionar este tipo de publicacións coa campaña que o Estado franquista desenvolvía co obxectivo de "erradicar la literatura popular en nombre de la verdadera cultura y de los principios morales del régimen» (Ruiz Bautista 2004: 243). Como exemplo destas actividades podemos citar:

El 15 de julio de 1942 la censura apercibe al I. N. L. E. de que es su criterio, a los efectos de aprobación de los planes editoriales, autorizar tan sólo «el mínimum de novelas de "tipo policiaco", donde abundan la degeneración, el juego, los vicios, venganzas, robos y crímenes». El ideal de la censura era llegar «a la completa suspensión de este tipo de obras», y especialmente «las traduciones (sic) americanas. (Ruiz Bautista 2004: 246).

San Gonzalo, en tanto que haxiografía, adáptase aos principios morais do réxime. Alén diso, o uso de repertorios fantásticos e medievais coincide en parte coa toma de posición de Ángel María Pascual ao publicar Amadis:

Amadís es el disfraz del nuevo prototipo de caballero, soldado y poeta que en Garcilaso se consiguió simbolizar. Pascual, desde su atalaya periodística en la revista Jerarquía que dirigía en Pamplona Fermín Yzurdiaga, se suma a esta campaña mistificadora y mitificadora con una interesante contribución narrativa: la puesta en circulación de la tópica de los libros de caballerías en su única novela, y en una secuela de difícil clasificación: Don Tritonel de España, un opúsculo que apenas enmascara de ficción caballeresca la clara finalidad panfletaria (de sorprendente modernidad editorial como libro de bolsillo) de la colección en que aparece: las Ediciones para el bolsillo de la camisa azul. (Gil González 1997: 135). En lugar dun cabaleiro, soldado e poeta, é un monxe guerreiro o que atopamos como protagonista de San Gonzalo. Podemos interpretar as manobras editoriais levadas a cabo desde os organismos do Estado como un intento do campo 
do poder de controlar o subcampo de grande produción ${ }^{10}$ a través da imposición, mediante recursos propios da ditadura, como a censura, duns criterios de xerarquización ideolóxicos que substitúan os criterios de xerarquización económicos.

Por outra parte, Cunqueiro utiliza en San Gonzalo elementos propios do imaxinario católico e do falanxista, pero tamén outros que son reivindicados con frecuencia desde o galeguismo. Encontramos alusións á batalla de Clavijo: «Como en Clavijo, al lado de Gonzalo, en el campo de Resende, había cabalgado en blanco caballo, el Hijo del Trueno con espada en la diestra» (Cunqueiro 1984: 145). Máis adiante, alúdese ao rei García de Galicia: «Gonzalo Arias quisiera preguntarle por el pobre Don García, aherrojado en Luna, muerto en los hierros, pero no quisiera recordar al viejo Andrade otros días» (Cunqueiro 1984: 149). Tamén podemos citar un fragmento como o seguinte:

Cercáronme as ondas do mar maior

e non hei barqueiro nen remador!

Cercáronme as ondas grandes do mar

e non hei barqueiro nen sei remar.

Estos versos del juglar Mendińo siempre me parecieron versos para decir a este mar, que no a las olas mansas y tibias de la isla de San Simón... Mar de Foz, mar de las Ballenas: esta es la hora de tu Lepanto. El sol, al pairo, para no perder ni por un instante la visión de la batalla, te ilumina. Un cielo profundo y azul, que surcan blancas y transparentes nubes de mayo, se espeja en ti. (Cunqueiro 1984: 172).

Relacionamos a utilización conxunta destes repertorios co que Andrea Geniola (2009) denomina oferta rexional franquista, consistente na articulación dun discurso sobre o rexional a través da creación de institucións culturais provinciais dependentes do CSIC que vehiculasen a erudición local ${ }^{11}$. Destaca Geniola algunhas tomas de posición no campo da historiografía que consideramos homólogas á de Cunqueiro no campo literario, no sentido dunha integración de

10 O subcampo de grande produción sería aquel «consagrado ao mercado e ao beneficio económico» (Bourdieu 2004: 32). Nel prevalecen os principios de xerarquización externa (que seguen criterios de triunfo temporal baseados no éxito comercial ou na notoriedade social), polo que ocupa unha posición heterónoma con respecto ao campo do poder (Bourdieu 2004: 29-30).

11 En Galicia, créase en 1943 o Instituto Padre Sarmiento, dependente do CSIC. Parte dos seus membros e dos seus fondos provińan do desmantelado Seminario de Estudos Galegos (Mato 2004: 35). 
elementos do imaxinario nacionalista catalán e vasco no imaxinario nacionalista español. O investigador non se ocupa do caso galego, pero se acudimos a unha das fontes que cita, Las Españas. Formación histórica. Tradiciones regionales, veremos que os tópicos identitarios manexados no capítulo titulado «Desde el Duero al Ortegal» son similares aos empregados polo nacionalismo galego decimonónico e por Cunqueiro en San Gonzalo:

En el futuro, hasta hoy, Portugal y Galicia serán brotes frondosos de aquel vástago druida de las selvas del Noroeste. Nada conseguirá truncar los motivos parentales de una afinidad de lengua, en el gesto humano, en el sentido de la vida, en el regusto sabroso por las mismas cosas íntimas, en la perennidad del lirismo céltico, en el miedo común ante los dioses tenebrosos de la bruma y de la selva, en la personificación de la naturaleza para el diálogo y para la queja dolorida en la incitante incomprensión. (Elías de Tejada 1948: 155).

Máis adiante, engade o autor: «Si algún pueblo tiene necesidad del paisaje circundante para completar su personalidad, ése es el celta» (Elías de Tejada 1948: 156). Non faltan tampouco nin a comparación con Escocia nin a alusión á Santa Compaña: «[...] el celta topa a sus dioses en la oscura fuerza incomprensible de los árboles de la selva o de las hiedras de las ruinas. Por eso todos los castillos de Escocia tienen un fantasma familiar y todos los gallegos han visto, al menos alguna vez en su vida, cómo rompe la negrura de las noches invernales la línea de puntos luminosos de la Santa Compaña trajinera» (Elías de Tejada 1948: 158). O sentimento de saudade é explicado pola situación xeográfica e polo xeito de se relacionar o carácter celta coa natureza:

Al personificarla [a natureza], se la teme: éste es el segundo esquema del diálogo entre el hombre y el árbol a que antes me refería. Temor de donde brota la superstición que empaña la religiosidad galaica y que produce el tema más auténtico que han legado a la cultura universal: la saudade o soidade, dicho respectivamente en portugués y en gallego. [...] Situadas las gentes celtas que han informado culturas peninsulares cara a la inmensidad del mar desconocido, su inmensidad ha azuzado el innato terror ante los espíritus que pueblan las olas o las selvas. (Elías de Tejada 1948: 167. Itálica no orixinal).

Cara ao final do capítulo, o autor dá a súa visión dunha Galicia integrada en España: 
No me cabe la menor duda de que, si Galicia hubiese derrotado al Océano con las proas de sus naos descubridoras, hoy su gente fuera tan finchada por lo menos como lo es la grey portuguesa. No fué así, y el sentimiento de inferioridad pervive. ¿¿Hasta cuándo? Esas son cuestiones de sociología que escapan al intento de este libro. El establecimiento del orgullo de lo español en el cuadro universal, rehacer la magnitud generosa de lo hispánico, es a mi juicio la única manera de cortar semejantes pesadumbres en la alada ilusión de una patria varia, una y capitana. No es ese sentimiento de inferioridad aquel rencor sordo que culmina en Rosalía de Castro; es un dolor colectivo que sólo con medicinas generales tiene cura. Las que no pueden ser otras que el restablecimiento de las dimensiones universales de España y la ponderación que en esa faena ha de corresponder a los celtas de la Galicia llena de dulzuras. (Elías de Tejada 1948: 182-183).

En termos de construción identitaria nacional, poderiamos dicir que a visión de Francisco Elías de Tejada coincide coa da corrente principal do nacionalismo galego (desde o século xix até a década de 1970 polo menos) ao presentar Escocia como un referente de analoxía ${ }^{12}$ (aínda que esta función fose máis claramente representada para o galeguismo por Irlanda) e Portugal como un referente de reintegración $n^{13}$. Porén, para expresar a diferenza entre as posturas nacionalistas galega e española (como a de Elías de Tejada), podemos recorrer ao concepto de referente de oposición, tomado de Justo G. Beramendi (1991), tal como é utilizado por E. J. Torres Feijó (2004: 442): «sistema do qual se pretende a emancipaçom e se gera umha actitude de rechaço». Este referente de oposición, identificado con Castela ou España, funcionaría no protosistema cultural galeguista ${ }^{14}$. Falamos dun imaxinario até certo punto coincidente, pero que pode ser manexado de diferentes formas e usado para diversos fins. Así, desde unha posición oposta ao carlismo de Elías de Tejada, o galeguista exiliado Luís Seoane insire ese imaxinario nunha

12 «Son aquellos entes nacionales con los que se compara positivamente el propio» (Beramendi 1991: 136). 13 «Evoca un ente nacional hermano — en realidad, una parte del propio— que se separó en el curso de la historia, a pesar de pertenecer al mismo tronco étnico o nacional» (Beramendi 1991: 136).

14 «O termo "galeguista" é usado aqui indicando o sentido da acçom dos agentes comprometidos no e com o PCuG [protosistema cultural galeguista] e PSLG. Entendemos por tal protossistema cultural aquele que, deficitário na conformaçom dos seus macro-factores sistémicos (tal como definidos por Even-Zohar 1990) pretende balizar-se a respeito doutros, particularmente do espanhol, invocando como norma sistémica fundamental (ainda que nem sempre única) o uso do galego» (Torres Feijó 2007: 689, n. 3). 
lińa histórica de pensamento progresista. Seoane ocúpase de Elías de Tejada na audición radial «Galicia Emigrante» emitida o 23 de outubro de 1958 ${ }^{15}$ :

Desde o mar Cantábrico até o rio Douro, desde pouco mais alá do rio Eo, xa en terra asturiana e nunha lińa vertical que faga ángulo recto co Douro, extende-se un territorio de «características uniformes, con flores, fauna y relieve sensiblemente iguales. Tierras de perenne verdor en contraste con las castellanas y portuguesas limítrofes», como escreve un escritor castellano que hai alguns anos escreveu un livro sobre Galícia, «La tradición gallega», que resalta, alén de certo sectarismo natural nun home de ideais contrárias [sic] politicamente aos liberais de Galícia, un dos mais importantes publicados nestes últimos vinte anos. Asi o deveu entender Otero Pedrayo ao fazer o prólogo e presentá-lo ao público leitor interesado en problemas galegos. [...] ainda que remate coa defesa dunha posición rexionalista pasada de oportunidade, como a defendia [sic] por Nocedal e Vázquez Mella, superada pola actual realidade galega, e tamén polo avance doctrinário da nosa época, todo o livro, ainda con erros, é un verdadeiro canto a Galícia e á sua persoalidade no conxunto de países da Península Ibérica. (Seoane 1994: 436-437).

En San Gonzalo, Cunqueiro utiliza elementos dun repertorio identitario galego que podemos definir como esencialista, identificábel a grandes trazos do nacionalismo galego do século XIX. Con todo, cómpre ter en conta que, se ben polo seu contexto editorial (sae nunha colección de biografías) a obra se achega ao campo historiográfico, xa desde o prólogo somos advertidos: «Se cuenta la vida de Gonzalo, dándole lo suyo a la historia y a la leyenda. No, no es esta una biografía novelada; en todo caso es la novela de Gonzalo Arias, santo y héroe» (Cunqueiro 1984: 129-130. Itálica no orixinal). Este hibridismo xenérico parece axeitado, en todo caso, para a utilización literaria dun imaxinario ligado á construción identitaria. Se, por unha parte, falamos do uso dun imaxinario que diferentes

15 Podemos pensar que a elección do tema desta audición de Seoane estivo motivada pola participación de Elías de Tejada no volume Homaxe a Ramón Otero Pedrayo no LXX aniversario do seu nacimento, editado por Galaxia en 1958. Sobre este asunto escríbelle desde Bos Aires a Fernández del Riego nunha carta datada o 18 de febreiro de 1958: «¿Como se pode admitir en silencio que Elías de Tejada nos invente unha Tradición e suxete a ela a Otero Pedrayo? Quixera que me respondeses a estas preguntas mińas, pois elas ándanme na cabeza desde a chegada do tomo a que me refiro. ¿Que queda da tradición tan nosa, dos Constitucionalistas, dos Precursores e das xentes de comezos de século?» (Fernández del Riego 2002: 126). Elías de Tejada tamén contribuíu cun artigo ao libro Ramón Otero Pedrayo. A súa vida e a súa obra. Homaxe da Galicia universal, editado en Caracas en 1958. 
grupos poden interpretar como rexional ou nacional, pola outra parte, podemos interpretar a publicación da «novela de Gonzalo Arias» como a proxección da historia ou lenda dun heroe local no ámbito nacional.

Un exemplo do emprego dese imaxinario en San Gonzalo témolo en certos treitos descritivos. María López Sández estudou en profundidade a forza performativa da descrición literaria da paisaxe en relación coa construción dun imaxinario territorial:

Por outra parte, o propio tratamento da paisaxe e o territorio nacional como algo distintivo, opositivamente delimitado fronte ao alleo - como é o caso, no discurso literario galego, da oposición constante entre os trazos de Galicia e Castela - e con afinidades territoriais como as estabelecidas polo atlantismo galego, tamén funciona performativamente, colaborando de xeito activo na conceptualización territorial da comunidade. Se non é posíbel comprender a imaxe actual de Londres sen Dickens, o imaxinario nacional galego dificilmente pode ser entendido sen Pondal, Pedrayo e tantos outros. Deste xeito, as descricións literarias da paisaxe terían, cando menos, dous efectos pragmáticos na comunidade de destino que potenciarían unha homoxeneidade cultural favorecedora do discurso nacionalista: por unha banda, contribuirían a crear e consolidar a noción dunha entidade territorial delimitada e, por outra, dotarían á comunidade da conciencia de ter un modo común e propio de relacionarse co medio, unha cultura que se traduciría nunha perspectiva cognoscitiva diferenciada e un xeito propio de «ver» e relacionarse co mundo. (López Sández 2006: 218).

No caso de San Gonzalo, consideramos que algunhas descricións están orientadas a delimitar fronte ao alleo, pero non funcionan opositivamente, senón complementariamente co imaxinario nacionalista español, nun sentido semellante ao que, no campo historiográfico, ocorría cos textos de Elías de Tejada.

Vexamos unha descrición onde a paisaxe se asocia ao referente celta: «El río Iso — un hada céltica, un hada de niebla — pasa cantando, a lo lejos, entre los adedules... En la lejanía, los últimos rayos del sol poniente iluminaban la cumbre del Pico Sacro. Allí estaba Compostela, la Barca y la Cueva, la fuente de misericordia...» (Cunqueiro 1984: 153). Ou tamén: «El Masma —un río que recuerda el Avon de Shakespeare, pero que yo he comparado con el Aulne bretón cuando pasa al pie de Cahaix cantando en bretón bretonante— (Cunqueiro 1984: 171). 
Noutras ocasións, as caracterizacións étnicas son directas: «En Mondoñedo lo espera el pueblo en el puente de San Lázaro. Desde los castros, vecinos de Pedrido, Cesuras, Oirán, Argomoso, han bajado los celtas de larga cabellera y ojos ingenuos y aurorales. El monje, con su pueblo, se arrodilla y hacia Dios suben los cantos de gracias» (Cunqueiro 1984: 175-176). O protagonista é descrito como segue: «Gonzalo es de casta germánica, guerrera y noble, pero su alma está conquistada por el encanto celta, por el hechizo de aquella raza sońadora y amorosa, creyente y dócil, que su báculo guía suavemente, como una vara de avellano, una manada de bueyes» (Cunqueiro 1984: 202).

A saudade e a morriña tamén se asocian á paisaxe: «El mar bizantino hizo que Gonzalo añorase el mar gallego, el verde y ronco mar de Foz, el boreal y duro mar de las Ballenas. Parecióle al obispo que tanta saudedá [sic] era señal de vejez. Paseando por la cubierta del navío sońaba con el invierno mindoniense, con la mansa orballada, con el gran fuego que ardía en la chimenea» (Cunqueiro 1984: 199). Outro exemplo sería: «Y sus más hermosas palabras fueron para declarar su morriña, el anhelo de volver a ver las amadas cumbres, los verdes pinares, los hondos valles, el mar de Foz...» (Cunqueiro 1984: 204). En San Gonzalo mesmo se fala da Santa Compaña (Cunqueiro 1984: 214-215), nunha narración referida explicitamente como de tradición oral ${ }^{16}$.

Inclinámonos a considerar San Gonzalo como integrante dunha tendencia subsistémica, na medida en que os elementos repertoriais vinculábeis ao galeguismo aparecen incorporados nunha perspectiva nacionalista española. Parecen funcionar, polo tanto, como normas de repertorio. Cómpre indicar, ademais, que se insistimos nestas características identitarias é porque nos parecen determinantes á hora de configurar a imaxe que Cunqueiro proxecta no sistema literario español en tanto que escritor galego.

16 «Y habiendo regresado Gonzalo Arias a su diócesis obró siete milagros, que aquí se cuentan puntualmente. Estos milagros de Gonzalo no están en los viejos códices, pero en mi tierra se cuentan. Yo los oí cien veces y otras tantas los conté. Al amor de la lumbre, en las largas noches de la invernía, contemplando la danza eterna y amorosa de las llamas en los troncos que arden en el hogar, he de contárselos a mis hijos para que ellos, cuando yo ya no esté y sea solamente el pálido reflejo de una voz oída alguna vez, puedan contárselos a los suyos» (Cunqueiro 1984: 209). 


\section{FLORES DEL AÑO MIL Y PICO DE AVE}

En 1968, ano de publicación de Flores del año mil y pico de ave, Cunqueiro, instalado en Galicia, traballa como director do Faro de Vigo ${ }^{17}$. Desde a década de 1950, retomara a produción literaria en galego, animado por Francisco Fernández del Riego. Esta actividade literaria está encadrada no proxecto cultural desenvolvido polo grupo de galeguistas reunidos ao redor da editorial Galaxia ${ }^{18}$.

A editorial Taber publica Flores del año mil y pico de ave na colección Ciempiés, dirixida por Joan Perucho. O volume é unha recompilación de narracións da primeira posguerra onde está incluída San Gonzalo. Na mesma colección, son publicados o propio Perucho e outros autores, como Baltasar Porcel e Néstor Luján, relacionados coa revista Destino, onde tamén colabora Cunqueiro ${ }^{19}$. Na mesma editorial aparecerán as recompilacións de artigos xornalísticos El envés, Laberinto y cía e mais El descanso del camellero. Alén disto, a editorial Destino (vinculada co semanario homónimo) publicará a maior parte da produción novelística de Cunqueiro en castelán. O centro editorial de Cunqueiro no sistema español, que no momento de publicación de San Gonzalo era Madrid, desprázase a Barcelona. Alí está tamén o centro editorial do boom.

Usamos o termo boom para designar o fenómeno comercial que se produciu no sistema literario español (especialmente a partir do grande éxito de Cien años de soledad, difundido en España a partir de 1968 [Pohl 2004: 166] pero con precedentes como o de La ciudad y los perros, de 1963) asociado á ocupación das posicións centrais do sistema por produtores hispanoamericanos, mediante tomas de posición no campo literario que articulaban repertorios asociados ao que se deu en chamar realismo máxico ou real marabilloso. No campo editorial, estes produtores estaban ligados a Seix Barral, editorial dirixida por Carlos Barral, e á axencia literaria de Carmen Balcells. Flores del año mil y pico de ave non participou do fenómeno comercial do boom, aínda que, como veremos, repercutiu no seu funcionamento no sistema literario. Cunqueiro nunca chegará a ocupar unha

17 Recuperara o carné de xornalista en 1962 (Franco Grande 1991: 566-567).

18 Pode verse unha definición do Grupo Galaxia desde o punto de vista sistémico en Samartim e Cordeiro Rua (2009: 174-175).

19 Nesta altura, o semanario xa se editaba en Barcelona e estaba afastado das súas raíces falanxistas. Para a participación de Cunqueiro en Destino, véxase María Liñeira (2004). 
posición central no sistema, a pesar de gañar visibilidade en 1969 tras recibir o premio Nadal por Un hombre que se parecía a Orestes. Segundo Dunia Gras Miravet e Pablo Sánchez López, o campo literario español reconfigurouse en relación cos produtores hispanoamericanos a partir de 1967 (tomando como referencia a data de publicación de Cien años de soledad):

El beneficio en los índices de jerarquización externa (éxito comercial, notoriedad social, etc.) demuestra que las relaciones de fuerza cambian a partir de 1967. Los escritores hispanoamericanos alcanzan una posición de protagonismo que resitúa a los autores españoles. Algunos consiguieron una posición complementaria, como Juan Marsé y Juan Goytisolo; pero también Camilo José Cela o Gonzalo Torrente Ballester parecieron adaptarse a la tendencia renovadora del discurso literario e intentaron cumplir con las exigencias estéticas que los latinoamericanos habían puesto de manifiesto. La relación en otros casos fue de antagonismo más o menos justificado: desde Isaac Montero y Antonio Martínez Menchén (preocupados por el descrédito del realismo) hasta los mediocres comentarios de José María Gironella (incapaz de admitir el poderío creativo de la literatura "colonial»), comentarios que incluso estimularon la publicación de un volumen de entrevistas a autores espańoles, concebido como tentativa de dilucidar hasta que punto era común esa opinión negativa. (Gras Miravet e Sánchez López 2004: 112-113).

En canto ao significado das etiquetas xenéricas realismo máxico e real marabilloso, aclararemos que desde 1955 e na década de 1960 os termos aparecen vinculados ao de literatura fantástica, segundo Alicia Llarena (1997: 108). Tamén se fan equivaler a literatura moderna ou nova narrativa (para dar conta da pegada formalista e surrealista dos produtos asociados ás etiquetas) e a literatura mítica (en tanto que privilexia motivos asociados ao imaxinario mítico americano). Por último, a autora sinala a utilización dos termos para referirse ás diferenzas culturais de Europa e América (Llarena 1997: 109-111).

É común entre os críticos argumentar que unha das razóns que explicarían o fenómeno do boom é o esgotamento dos modelos realistas de novela. Tendo isto en conta, debemos preguntarnos por que Cunqueiro non accedeu ao centro do sistema, especialmente tratándose dun produtor xa presente no campo español, cuxa centralidade non provocaría as polémicas derivadas do balizamento nacional do sistema literario que efectivamente se produciron (Gras Miravet e Sánchez López 2004: 134 e ss.). Unha das razóns da marxinalidade da produción de 
Cunqueiro podemos deducila do estudo dos paratextos utilizados para vender os produtos dos novelistas hispanoamericanos que leva a cabo Burkhard Pohl:

La interpretación del texto, tal como se da en el peritexto editorial, se mueve entre los polos de espejismo realista y experimentación formal. Aún bajo el impacto del realismo social, al comienzo de los años sesenta la presentación de los textos se orienta por las implicaciones político-miméticas, llevando a cabo una lectura translaticia. [...] El paradigma realista no impide un cierto exotismo en la presentación paratextual del texto ajeno; exotismo que se mantiene no como fin en sí, sino dentro de una lectura política determinada. Por otro lado, destaca, en particular en las ediciones publicadas por Carlos Barral, la inscripción del autor latinoamericano en una tradición literaria común que reivindica un cuestionamiento de la supuesta nacionalidad literaria. La creciente intercomunicación de las metrópolis literarias, en cuyo proceso las editoriales constituyen un factor esencial, lleva a la formulación de discursos homogéneos de índole "transnacionalista», mantenido y divulgados tanto por escritores de la nueva narrativa latinoamericana como por parte de la intelligentsia izquierdista europea, discursos que traslucen en los peritextos de las editoriales relacionadas con el boom. Por último, en la publicidad propiamente dicha, prevalece el lema del boom como referente obligatorio y grato; el cual consigue establecer también un protagonismo del artista latinoamericano, como parte de una nómina de autores estrella, en los medios de comunicación españoles. (Pohl 2004: 187).

Cunqueiro non é latinoamericano nin descoñecido no sistema español, pero, á parte disto, interésanos destacar que os axentes ligados á difusión do boom mantiñan posicións de esquerda no campo político. Por outra banda, a produción de Cunqueiro na altura non era valorada como vangarda artística, carecía da marca de renovación e «experimentación formal» que se asociaba aos produtos hispanoamericanos (aínda que posteriormente a crítica puxera de relevo estes aspectos da súa produción literaria). Se Cunqueiro ten unha imaxe exótica no sistema español, como efectivamente apunta Rexina Rodríguez Vega (2001), está ligada a unha percepción estereotípica da cultura galega ${ }^{20}$. Se atendemos aos paratextos presentes nos seus libros, comprobamos que a súa produción é vendida como fantástica e culturalista, o que podería coincidir a grandes trazos con algúns pro-

20 Porén, non son raras as manifestacións de desacordo do propio Cunqueiro con esa imaxe, sobre todo cando se asocia ao celtismo (que a finais do período franquista estaba desprestixiado e comezaba a rexeitarse desde algunhas posicións do protosistema galego) ou ao pintoresquismo de aparencia etnográfica. 
dutos do boom, pero non coa súa proxección no mercado. Favorécese a súa imaxe de fabulador e de prosador poético, un galego de carácter tendente ao lúdico e ao lírico, afastado da realidade social. Podemos interpretar nese sentido a seguinte declaración do propio Cunqueiro sobre San Gonzalo, do que obvia a lectura política ${ }^{21}$ : "Co seudónimo de Álvaro Labrada fixen unha haxiografía inventada que algúns tomaron en serio, incluso eruditos medievalistas, San Gonzalo, obispo de San Martín de Mondoñedo que derrotou aos normandos rezando avemarías» (Margarita Ledo Andión, "Entrevista inédita do ano 1973», Coordenadas no 2, Santiago, 1982, apud Nicolás [1994: 123]).

Ademais, a crítica afín contribuía a difundir esa imaxe. No número 646 de Gaceta ilustrada (do 23 de febreiro de 1969) publicaba Antonio Tovar unha recensión de Flores del año mil y pico de ave da que citamos uns fragmentos a seguir:

Su estilo es para nuestro común idioma algo del regalo del de Valle Inclán. Palabras que saben a la gleba húmeda de Galicia, y verbos poetizados por la falta de pronombre reflexivo $[\ldots]$

Para mí en estas fantásticas historias de la primera parte, El Caballero, la Muerte y el Diablo, tenemos ya en todo su brillo la fantasía inagotable de Cunqueiro, que brota a la vez de esa sobarbada vena de burla gallega que lleva a dudar al lector más incrédulo sobre los límites de la tomadura de pelo en las bravas costas de los mares célticos. [...]

Lo que mantiene vivas estas páginas de Cunqueiro no es el histórico esteticismo que las condimenta, ni la erudición tan exquisita como inventada, sino los sabores y colores, la presencia del paisaje y del habla del terruño, las voces de los hombres y el silencio de las mozas alrededor de una mesa de taberna donde se escancia, desde bien alto, el vino en la taza. $[\ldots]$

Y Cunqueiro, desde Galicia, sigue contribuyendo a la literatura moderna con alma fantástica que habita un cuerpo sin mecanizar. (Tovar 1972: 84-86).

21 Por outra parte, as propias opinións políticas de Cunqueiro non contribuían a favorecelo entre os axentes vinculados coa esquerda: «Estoy por la paz, por el colonialismo, contra la independencia de los Congos, contra el comunismo, por la unidad de Europa, porque en la ONU el voto de Nigeria no valga lo que el de Portugal o Irlanda, contra la bomba atómica, etc. Y no me caen simpáticos ni Castro, ni Nasser, ni los socialistas belgas» (J. R. Díaz García, «La figura y sus hechos. Álvaro Cunqueiro», Faro de Vigo, c.1962, apud Nicolás [1994: 259]). 
Temos, pois, as referencias ao céltico, á literatura fantástica, a mención ao humor e á calidade galega da lingua, a importancia do sentimento da paisaxe e o culturalismo, sen esquecer a vinculación de Cunqueiro con repertorios asociados ao etnográfico, como pode ser o gastronómico.

Por outra banda, atopamos reivindicacións fundamentadas na comparación coa produción maxicorrealista vinculada ao boom. Podemos exemplificalas cunhas declaracións de Torrente Ballester:

Cunqueiro fantasea tan bien como Borges y escribe bastante mejor. La originalidad de Cunqueiro está por estudiar, sí, pero yo aseguro que es mucha y grande. Imaginemos ahora que Cunqueiro da dos o tres conferencias sobre sí mismo, asiste a coloquios y a cenas literarias, que comparece ante las cámaras de TV y todo lo demás. Estoy seguro de que el antes mencionado surtidor de luz y de ingenio brotaría, inagotable, en la árida capital de la árida meseta. Y los pocos comparecientes marcharían decepcionados porque Cunqueiro no había resuelto ni el enigma del Universo ni la situación del tercer mundo [...]. Lo que Triunfo no preguntó [en referencia a unha entrevista con Borges] fue el por qué instrumentos poderosos de propaganda favorables a este y a otros escritores hispanoamericanos, excluyen por sistema a los españoles. (Torrente Ballester, Faro de Vigo, 23-V-73, apud Rodríguez Vega 2001: 210).

Pola súa parte, Antonio Iglesias Laguna (1970: 16 n. 10) emprega o termo «realismo mágico» para referirse a Cunqueiro, García Márquez e Ramón J. Sender. Máis adiante, declara o seguinte:

$Y$ que las innovaciones formales hispanoamericanas, tan admiradas hoy entre nosotros, se experimentaron en España antes que en Hispanoamérica o, por lo menos, simultánea e independientemente. Bastaría para demostrarlo la lectura de ciertas obras de Ramón J. Sender, Rafael Dieste, Samuel Ros, Vicente Risco y Álvaro Cunqueiro. Por lo demás, en cuanto a fantasía, técnica y experimentación con el lenguaje, no creo que Luis MartínSantos, Rafael Sánchez Ferlosio, Antonio Prieto, Juan Perucho, y José María Guelbenzu sean inferiores a nuestros hermanos de América. (Iglesias Laguna 1970: 24).

Santos Sanz Villanueva tamén utiliza a etiqueta de «realismo mágico» para referirse á produción do mindoniense. As obras onde máis destacarían as características do xénero (combinación de realidade e fantasía, deformación do espazo e do tempo e "Historia en la historia») serían San Gonzalo, Las crónicas del sochantre e Un hombre que se parecia a Orestes (Sanz Villanueva 1972: 110). 
É precisamente no ámbito da crítica e no dos monográficos sobre novela (que poderíamos situar nun lugar intermedio entre a crítica e a historiografía) onde observamos con claridade dous fenómenos determinantes na posición de Cunqueiro no sistema literario español: as homoloxías co campo político, por unha parte, (que desembocarán en boa medida en acusacións de escapismo desde posicións de esquerdas) e a acción constritiva da literatura nacional entendida como subsistema de codificación secundaria (que privilexia repertorios realistas e exclúe a produción literaria non escrita en español). Desta maneira, atopamos tomas de posición como a de Juan Ignacio Ferreras, con Tendencias de la novela española actual (1931-1969), publicado en París, que emprega no seu estudo sobre novela española a socioloxía marxista. A única tendencia que lle interesa é a da novela realista:

Bueno es, a la hora de juzgar 30 años de novela, el comprobar la existencia de un grupo de escritores que intentan abrir nuevos horizontes a la Literatura novelesca; pero desgraciadamente para García-Viñó y para su grupo, la realidad social española — como tantas veces he repetido a lo largo de este libro - es demasiado determinante o demasiado invasora; su presencia es tan opresiva que ante ella sólo se pueden adoptar, en buena lógica, dos posiciones y las dos intelectuales: o aceptarla o negarla. Si se la acepta, la problemática novelesca se vuelve, más tarde o más temprano, crítica y hasta social (sirva de ejemplo la obra de Luis Romero), y si no se la acepta, el escapismo también aparece más tarde o más temprano (sirva de ejemplo las obras de Cunqueiro o la última novela Don Juan, de Torrente Ballester). (Ferreras 1970: 194).

Vexamos a tradición nacional de novela realista castelá en que Pablo Gil Casado insire a novela social da altura:

A la luz de las obras estudiadas se puede llegar a la conclusión de que la novela «social» española representa la continuación de la tradición literaria castellana. La evolución, claro es, se ajusta a la concepción artística de diferentes épocas, pero el análisis de la sociedad se encuentra no solamente en el período que sigue a la guerra, sino también en el que la precede, en los escritores del noventaiocho, en las obras del naturalismo, en el realismo pleno, en el realismo de transición. Así, se puede establecer una línea realista que comprendería, enlazándolos, a Goytisolo-Cela-Zunzunegui-Sender-Baroja-Blasco Ibáńez-Clarín-Galdós; o se puede trazar una serie de relaciones para ver como cómo el lirismo neorromántico de una Concha Espina se continúa en Arconada y llega a López 
Pacheco, o cómo ciertos temas se repiten e repiten: el de la vida del empleado ya está en Galdós, el del minero en Ciges Aparicio, el del campesino explotado en Blasco Ibáńez, el examen de la crisis de la sociedad en la generación del noventaiocho, en Larra, en Cadalso. (Gil Casado 1968: 195).

Por outra banda, desde o campo universitario son atacados os traballos de Iglesias Laguna (1970)22 e García-Viñó (1967)²3, precisamente os máis eloxiosos con Cunqueiro.

Volvamos agora á imaxe de Cunqueiro en tanto que escritor galego prototípico no sistema literario español. Para comprobar cal é a imaxe da literatura galega que desde o protosistema galego pretende proxectarse no sistema espańol, debemos referirmos ao número 152/153 da revista Ínsula, publicado en 1959, especialmente dedicado á literatura galega ${ }^{24}$. Nel aparece o ensaio "Factores esenciales de la literatura gallega», onde Ramón Piñeiro (axente central do Grupo Galaxia e do protosistema cultural galeguista da altura) estabelece as marcas identitarias que considera consubstanciais á literatura galega: o lirismo, o humorismo e o sentimento da paisaxe, cuxo vehículo de expresión privilexiado sería o idioma galego ${ }^{25}$.

Tales trazos non parecen diferir en exceso das utilizadas polo nacionalismo galego decimonónico na caracterización nacional de Galicia e, á vez, coinciden en gran parte coas calidades distintivas mediante as que parte da crítica do sistema literario español conforma a imaxe exótica de Cunqueiro. Con todo, non debe-

22 «[...] Treinta años de novela española (1938-1968), de Antonio Iglesias Laguna, obra parcial, injusta y falsamente valorativa, completamente indispuesta a aceptar las raíces reales de nuestra novela actual. Bajo la falsa pretensión de objetividad, el autor mezcla autores de la más distinta calidad, en los que censura, eso sí, fallos de construcción que serían de menor importancia en la novela de nuestros años si detrás de ellos existiera auténtica problemática» (Sanz Villanueva 1972: 29).

23 «El lector del presente libro verá, páginas adelante, que no me satisface ni mucho ni poco el manifiesto de Manuel García-Viñó, disfrazado de monografía. Aunque en el se contengan algunas verdades, la generalidad del estudio es notablemente partidista» (Sobejano 1975: 11).

24 Segundo X. L. Franco Grande (2004: 133-135), foi Ramón Pińeiro quen se encargou de coordinar a preparación dos traballos para o número. A revista era ben vista desde o Grupo Galaxia polo seu antifranquismo e a súa boa acollida entre os universitarios.

$25 \mathrm{Na}$ «Carta a Daniel Cortezón Álvarez», unha toma de posición orientada cara ao interior do protosistema literario galego, R. Piñeiro tamén leva a cabo unha definición de carácter esencialista da literatura galega. Estaría caracterizada pola imaxinación, o humorismo e mais o lirismo. Os máximos representantes desas tendencias serían Fole e Cunqueiro (aos que se uniría no cultivo do modelo o propio Cortezón). Relacionado coa imaxinación estaría o misterio na literatura de Fole e a fantasía na de Cunqueiro, que proviría da tradición popular. 
mos esquecer que un dos obxectivos do Grupo Galaxia é instaurar lexitimamente o uso do galego como norma sistémica e isto advírtese en todo o conxunto de artigos que os axentes vinculados con Galaxia publican no referido número de Ínsula. Só se considera literatura galega aquela escrita en galego ${ }^{26}$. Deste xeito, as características descritas por Piñeiro (agás o idioma ${ }^{27}$ ) parecen funcionar como normas de repertorio tanto no protosistema galego como no sistema espańol.

Con respecto ás comparacións relacionadas co realismo máxico, entendemos que Cunqueiro e outros axentes que utilizan repertorios semellantes ou que se atopan en posicións similares, marxinais no sistema literario español, pasan a ser reivindicados para defender a existencia dunha produción literaria nacional equiparábel á dos autores do boom. O caso paradigmático podería ser a mención conxunta de Perucho e Cunqueiro, que se tornou case tópica, mesmo en críticas favorábeis aos autores latinoamericanos:

Una pregunta que debe, por el momento al menos, permanecer sin respuesta es: ¿̇a qué se debe el éxito de Cien años de soledad?, y su consecuencia lógica: ¿̨uáles son los ingredientes que han interesado al público? Si nos atenemos al atractivo de la imaginación desbordante, sin salir de la Península, encontramos ejemplos muy claros y eficaces de cultivo de lo imaginario: Juan Perucho y Álvaro Cunqueiro, según sus particulares sistemas. No es, pues, sólo lo imaginario lo que aporta García Márquez a la novela, ni siquiera estilo, cuidado hasta el límite. (Marco 1972: 52).

Propomos considerar este tipo de reivindicacións como parte dun proceso de emerxencia alternativa, na medida en que unha vez que o centro do sistema literario español é ocupado por axentes e produtos que non se adaptan a determinados trazos da literatura nacional (por tratarse fundamentalmente de autores estranxeiros e de obras afastadas do canon realista), prodúcese mediante as ditas

26 Isto non impide que desde o Grupo Galaxia se utilice tamén a produción en español de Cunqueiro para prestixiar a produción literaria do protosistema galego, de tal maneira que na revista Grial aparece unha recensión de Flores del año mil y pico de ave asinada por S. L. (Salvador Lorenzana, pseudónimo de Fernández del Riego).

27 Aínda que o uso de galeguismos pode ser celebrado e asociado á poeticidade da lingua, como vimos na recensión que A. Tovar facía de Flores del año mil y pico de ave. 
reivindicacións a oferta dunha «new selective tradition parallel to the hegemonic (alternative literary emergence $\left.{ }^{28}\right) »($ Domínguez 2006: 7).

\section{APUNTAMENTOS FINAIS}

Flores del año mil y pico de ave seguiu funcionando no sistema literario español despois da morte de Cunqueiro a través de dúas edicións en Seix Barral (1984 e 1990), que fora a editorial insignia do boom. Non nos ocuparemos polo miúdo disto, pero gustaríanos constatar que continuamos atopando o mesmo tipo de reivindicacións e ataques. Torrente Ballester di no prólogo escrito para a edición de 1984 de Compostela y su ángel (publicada orixinalmente tres anos despois que o San Gonzalo de Cunqueiro):

No se llevaba todavía [na década de 1940] esa manera de escribir, y la verdad es que, salvo lo de Cunqueiro y lo mío, las directrices estéticas apuntaban a otras metas. Álvaro Cunqueiro y yo coincidíamos, al menos, en partir del gallego (él, por entonces, escribía casi siempre en castellano) y en aspirar a la creación de un mundo lírico y fantástico, divertido y conmovedor, que se mantuviese por sí mismo en pie, si bien al mío propio, como señal distintiva, se le pudiera añadir lo de intelectual. Aquellos desmesurados maestros de la crítica de entonces, y muchos de la de ahora, ni hicieron caso a Cunqueiro ni me lo hicieron a mí. Ninguno de ellos podía comprender que se escribiera asi en aquellos tiempos, si bien sea cierto que ellos no entendían de estas ni de otras escrituras, y ahí están sus vaciedades para comprobarlo. Y cuando modos de escribir afines (lenguaje, imaginación, fantasía, música) irrumpieron desde otros lugares, irrumpieron inesperadamente, igual que una emboscada, a nosotros se nos hizo discípulos de los que podían, por sus años, serlo nuestros. La falta de rigor y de honradez de quienes por entonces tenían por el mango la sartén de los juicios literarios, vinieran de la diestra, vinieran de la siniestra, es un aspecto de nuestra cultura contemporánea que sólo conviene dilucidar a medias y con carga política en la decisión. (Torrente Ballester 1984: 11-12).

28 «Alternative emergence should be understood in polysystemic terms as a subsystem that, rather than attempt to free itself from the system in which it is integrated, identifies, through the proposition of a parallel canon, those practices and meanings which to date have been excluded from it — some of which eventually end up being incorporated into the hegemonic system» (Domínguez 2006: 8). 
Elena Quiroga cita unha conversa con Cunqueiro no seu discurso de ingreso na Real Academia Española, que dedica ao mindoniense:

Algunos críticos, sin pararse a observar la prioridad en el tiempo, han hallado ciertas semejanzas entre «Cien años de soledad», de García Márquez —e incluso con Sábato—y el «Merlín y familia» de Cunqueiro. Si le comentaba, sin concederle la menor importancia —nada de lo que se decía sobre su obra influía en ella, o le hacía variar- se alzaba apenas de hombros, y replicaba, bonancible:

Yo lo hice antes.

Y era verdad. Álvaro empezó sus narraciones mágicas en el año 1939, y publicó «Merlín» en 1955, adelantándose a la gran explosión de la novela hispanoamericana. (Quiroga 1984: 73-74).

Como exemplo de crítica, podemos citar a de Julio Rodríguez-Puértolas no seu Literatura fascista española: «Nada absolutamente en estas narraciones maravillosas recuerda ni la realidad ni mucho menos la ideología original de su autor, unas narraciones situadas, en plena conciencia, al margen de la Historia, en el reino de la imaginación» (Rodríguez-Puértolas 1987: 534). Denuncia mesmo o «extraordinario éxito» de Cunqueiro (quizais tomando en consideración os premios que recibiu):

Salvo ocasionales disonancias, la obra imaginativa de Álvaro Cunqueiro —no sin conexión con la parte mágica de lo real-marabilloso latinoamericano- ha logrado extraordinario éxito, por razones, sin duda, no muy difíciles de comprender. Las opiniones de Cunqueiro en contra del «escritor militante», y aún más, en contra de la sociedad moderna, son tajantes, y, sin duda, atractivas para muchos: exigiría el establecimiento de reservas de salvajes, de indios, en las que vivir fuera del poder de la técnica y de la democracia centralista. (Rodríguez-Puértolas 1987: 535).

No ano 2000, a editorial Ir Indo publica unha tradución para o galego de San Gonzalo. Deste xeito, unha editorial relativamente nova pon no mercado unha obra pouco coñecida dun autor canónico, cuxa produción en galego está publicada en Galaxia. Resulta interesante, para comprobar o nivel canónico de Cunqueiro na literatura galega e comparalo co da española, atender á «nota de edición» coa que se abre o volume. A obra é descrita así: «A historia relata a biografía de Gonzalo Arias, bispo de Mondoñedo alá polo ano mil. A súa andaina 
relátase a través dunha imaxinación desbordante que se basea na esaxeración, nos sońos delirantes do seu personaxe e no ritmo acelerado de imaxes para acadar ese xusto equilibrio entre realidade e lenda» (Monteagudo Cabaleiro 2000: 5). Máis adiante, despois de dar conta da riqueza léxica do texto, infórmasenos: «A presente edición trata de respectar coa maior fidelidade posible os trazos lingüísticos do autor; así, conservamos a utilización de voces como: naide, nao, quizabes, verba, pravias, meiresa, pilongas, francíxena (dos francos), cimos (das árbores), etc.» (Monteagudo Cabaleiro 2000: 6).

É indicativo da canonicidade de Cunqueiro o feito de que a tradución se faga co criterio de respectar os seus trazos lingüísticos (o emprego da lingua galega continúa a funcionar nesta altura como norma sistémica), pero agora interésanos máis centrármonos na lectura que se ofrece da obra. Pásanse por alto as implicacións políticas e destácanse as calidades relacionadas coa imaxinación e o carácter fantástico, nuns termos que poderiamos asociar sen moita dificultade a unha etiqueta xenérica como a de realismo máxico. Isto levaríanos a formular a hipótese da canonización de Cunqueiro no contexto dun proceso de emerxencia oposicio$n a l^{29}$, vinculado a tendencias protosistémicas (xa en vida do autor), ademais de suscitar a cuestión de en que medida persisten no presente os criterios valorativos do Grupo Galaxia no sistema de codificación secundario literatura galega.

Para finalizar, realizaremos unha pequena síntese do exposto. Consideramos que a utilización en San Gonzalo de determinados elementos mitificados asociados ao imaxinario nacionalista galego xunto con outros referentes ao imaxinario falanxista e católico pode entenderse como unha tendencia subsistémica na medida en que funciona a rexionalización dun repertorio entendido como nacional polos grupos galeguistas. É preciso ter en conta a relación de Cunqueiro con Falange no momento de produción de San Gonzalo para entender esta toma de posición. A partir da publicación de Flores del año mily pico de ave, o relato parece perder as súas connotacións políticas (excepto para algúns axentes de esquerdas) e pasa a ser relacionado con outra produción periférica con respecto ao sistema español como é a de J. Perucho, produtor bilingüe en catalán e castelán e próxi-

29 «Oppositional emergence [...] tries to break away from the hegemonic system and convert itself into a dominant system with its own independent canon, as exemplified by the counterperformance of its subsystems of secondary codification» (Domínguez 2006: 8). 
mo, coma Cunqueiro, ao ámbito da editorial Destino. Algúns axentes pretenden integrar no canon da literatura española esta produción, ao considerala homologábel cos repertorios identificados co realismo máxico que, a través do fenómeno do boom, se tornaran centrais no sistema literario español. Propomos estudar isto como un proceso de emerxencia alternativa. 


\section{REFERENCIAS BIBLIOGRÁFICAS}

Armesto Faginas, X. L.: Cunqueiro. Unha biografía, Vigo, Xerais, 1991.

Beramendi, J. G.: «El Partido Galleguista y poco más: organización e ideologías del nacionalismo gallego en la II República», en Justo González Beramendi e Ramón Máiz (comps.): Los Nacionalismos en la España de la II República, Santiago de Compostela / México, Consello da Cultura Galega / Siglo Veintiuno, 1991, pp. 127-170.

Bourdieu, P.: O campo literario, Bertamiráns, Laiovento, 2004.

Cunqueiro, Á.: La historia del caballero Rafael, Madrid, Vértice, 1939.

Cunqueiro, Á.: Las crónicas del sochantre, Barcelona, AHR, 1959.

Cunqueiro, Á.: Flores del año mil y pico de ave, Barcelona, Taber, 1968.

Cunqueiro, Á.: El envés, Barcelona, Taber, 1969.

Cunqueiro, Á.: Un hombre que se parecía a Orestes, Barcelona, Destino, 1969

Cunqueiro, Á.: Laberinto y Cía., Barcelona, Taber, 1970.

CunqueIro, Á.: El descanso del camellero, Barcelona, Taber, 1970.

Cunqueiro, Á.: Flores del año mil y pico de ave, Barcelona, Seix Barral, 1984.

Cunqueiro, Á.: Flores del año mil y pico de ave, Barcelona, Seix Barral, 1990.

Cunqueiro, Á.: San Gonzalo, Vigo, Ir Indo, 2000.

Cunqueiro, Á.: Obras literarias en castellano, 2 v., Madrid, Fundación José Antonio de Castro, 2006.

Domínguez, C.: «Literary Emergence as a Case Study of Theory in Comparative Literature», en CLCWeb: Comparative Literature and Culture 8.2. (2006). Accesíbel en <http://docs.lib.purdue.edu/clcweb/vol8/ iss2/1>. Última consulta: 14 de xullo de 2011.

Fernández del Riego, F.: Cartas de Luis Seoane desde o exilio, Sada (A Coruña), Ediciós do Castro, 2002.

Ferreras, J. I.: Tendencias de la novela española actual (1931-1969), París, Ediciones Hispanoamericanas, 1970.

Franco Grande, X. L.: «Expulsión e readmisión do periodista Álvaro Cunqueiro», A Trabe de Ouro, 8 (1991), pp. 563-572.

Franco Grande, X. L.: Os anos escuros. A resistencia cultural dunha xeración, Vigo, Galaxia, 2004.

García Márquez, G.: Cien años de soledad, Buenos Aires, Sudamericana, 1967.

Geniola, A.: «Erudición y particularismo. Sobre la "oferta regional” franquista», 2009. Accesíbel en: <http:// investigadoresfranquismo.com/pdf/comunicacions/mesa3/geniola_3.pdf>. Última consulta: 14 de xullo de 2011.

Gil CASAdo, P: La novela social española (1942-1968), Barcelona, Seix Barral, 1968.

Gil González, A. J.: Teoría y crítica de la metaficción en la novela española contemporánea. A propósito de Álvaro Cunqueiro y Gonzalo Torrente Ballester, Salamanca, Universidad de Salamanca, 1997.

GonZÁLEZ-Millán, X.: «Do nacionalismo literario a unha literatura nacional. Hipóteses de traballo para un estudio institucional da literatura galega», Anuario de Estudios Literarios Galegos 1994 (1995), pp. 67-81.

Gras Miravet, D.; SÁnchez López, P: «La consagración de la vanguardia (1967-1973)», en J. Marco e J. Gracia (eds.), La llegada de los bárbaros. La recepción de la narrativa hispanoamericana en España, 19601981, Barcelona, Edhasa, 2004, pp. 107-152.

Iglesias Laguna, A.: Treinta años de novela española. 1938-1968. Madrid, Prensa Española, 2a ed., 1970. Labrada, Á. (Álvaro Cunqueiro): San Gonzalo, Madrid, Editora Nacional, 1945. 
LiÑ́eIrA, M.: «Os cans fieis das verbas. Laberinto y cía. A sección de Álvaro Cunqueiro no semanario catalán Destino", Anuario de estudios literarios galegos, ano 2004 (2004), pp. 40-51.

Llarena, A.: «Un balance crítico: la polémica del realismo mágico y lo real maravilloso americano (19551993)», Anales de Literatura Hispanoamericana, 26 I (1997), Madrid, UCM, pp. 107-117.

López Sández, M.: A descrición topográfica: o seu papel na construción dun imaxinario cultural no discurso literario galego (Cantares gallegos, Arredor de si e o ciclo textual de Tagen Ata), Santiago de Compostela, Universidade, 2006.

L[orenzana], S. (Francisco Fernández del Riego): «Flores del año Mil y Pico de Ave, por Álvaro Cunqueiro», Grial, 23 (1969), pp. 120-123.

Mainer, J-C. (ed.): Falange y literatura, Barcelona, Labor, 1973.

Marco, J: «La imaginación desbordante: los últimos cuentos de Gabriel García Márquez», La Vanguardia, 22 de xuño de 1972, p. 52.

Monteagudo Cabaleiro, Ma . T.: «Nota de edición», en Álvaro Cunqueiro, San Gonzalo, Vigo, Ir Indo, 2000, pp. 5-6.

Nicolás, R. (ed.): Entrevistas con Álvaro Cunqueiro, Vigo, Nigra, 1994.

Otero Pedrayo, R.: A romeiría de Gelmírez, Santiago de Compostela, Editorial Nós, 1934.

Piñeiro, R.: «Carta a Daniel Cortezón Álvarez», en D. Cortezón, As covas do rei Cintolo, Vigo, Galaxia, 1956.

Pińeiro, R.: «Factores esenciales de la literatura gallega», Insula, 152/153 (1959), pp. 13-27.

PoнL, B.: «Vender el boom: el discurso de la difusión editorial», en J. Marco e J. Gracia (eds.): La llegada de los bárbaros. La recepción de la narrativa hispanoamericana en España, 1960-1981, Barcelona, Edhasa, 2004, pp. 165-205.

Quiroga, E.: Presencia y ausencia de Álvaro Cunqueiro. Discurso leído el día 8 de abril de 1984, en su recepción pública, por... Elena Quiroga y de Abarca. Y contestación del Excmo. Sr. don Rafael Lapesa Melgar, Madrid, Real Academia Española, 1984.

Rodríguez Fer, C.: A literatura galega durante a Guerra Civil, Vigo, Xerais, 1991.

Rodríguez Fer, C.: «Da romaría de Otero á romaría de Cunqueiro», en A. Tarrío (coord.): Álvaro Cunqueiro, Santiago de Compostela, Universidade, 1992, pp. 59-68.

Rodríguez-Puértolas, J.: Literatura fascista española v. I. Historia, Madrid, Akal, 1986.

Rodríguez de TejadA, F.: Las Españas. Formación histórica. Tradiciones regionales, Madrid, Ediciones Ambos Mundos, 1948.

Rodríguez VeGA, R.: «Estraña ave do paraíso. A recepción da obra cunqueiriana na literatura castelá», Anuario de estudos literarios galegos (2001), pp. 201-223.

Ruiz Bautista, E.: «En pos del "buen lector”: censura editorial y clases populares durante el Primer Franquismo (1939-1945)», Espacio, Tiempo y Forma, Serie V, Ha Contemporánea, t. 16 (2004), pp. 231-251.

Ruiz Carnicer, M. A.: «La cultura del poder. Propaganda en la alta manera», en J. Gracia García e M. A. Ruiz Carnicer, La España de Franco (1939-1975). Cultura y vida cotidiana, Madrid, Síntesis, 2001, pp. 155-185.

Samartim, R. e G Cordeiro Rua: "O Pensamento cultural galego em referência a Portugal : posiçom e funçom de ideias e grupos no tardofranquismo e na transiçom", en O Pensamento galego entre 1850 e 2000, V. 3, Porto, Universidade Católica Portuguesa - Imprensa Nacional-Casa da Moeda, 2009, pp. 171-191.

SeoAne, L.: «Galicia Emigrante» (1954-1971). Escolma de textos da audición radial de Luís Seoane. Versión galega e edición de Lino Braxe e Xavier Seoane, L. Braxe e X. Seoane (eds.), Sada (A Coruña), Ediciós do Castro, 2a ed., 1994. 
Sobejano, G.: Novela española de nuestro tiempo (En busca del pueblo perdido), Madrid, Prensa Española, 1975.

Torrente Ballester, G.: Compostela y su ángel, Barcelona, Destino, 1984.

Torres Feijó, E. J.: «Contributos sobre o objecto de estudo e metodologia sistémica: sistemas literários e literaturas nacionais», en A. Abuín González e A. Tarrío Varela (eds.): Bases metodolóxicas para unha historia comparada das literaturas na Península Ibérica, Santiago de Compostela, Universidade, 2004, pp. 423-444. Torres Feijó, E. J.: «O 25 de Abril e as suas imediatas conseqüências para e no protossistema cultural galeguista», en H. González e Ma X. Lama (eds.): Actas do VII Congreso da Asociación Internacional de Estudos Galegos, Sada (A Coruña), Ediciós do Castro - AIEG - Universitat de Barcelona, 2007, pp. 689-701.

Tovar, A.: Novela española e hispanoamericana, Madrid-Barcelona, Alfaguara 1972.

VV. AA.: Homaxe a Ramón Otero Pedrayo no LXX aniversario do seu nacimento, Vigo, Galaxia, 1958.

VV. AA.: Ramón Otero Pedrayo. A súa vida e a súa obra. Homaxe da Galicia universal, Caracas, [Centro Galego], 1958.

Vargas Llosa, M.: La ciudad y los perros, Barcelona, Seix Barral, 1963. 
